\title{
"AVALIAÇÃO dA dOR EM PACIENTES SUBMETIDOS À CIRURGIA DA TIRÓIDE PELA APLICAÇÃO DO MÉTODO DA ESCOLA DIFERENCIAL SEMÂNTICA DE OSGOOD“
}

\author{
Wanda de Aguiar Horta* \\ Zuleika Mendonça Kannebley**
}

\begin{abstract}
RBEn/06
HORTA, W.A. \& Kannebley, Z.M. - Avaliação da dor em paciente submetidos à cirurgia da tiróide pela aplicação do método da Escola diferencial semântica de Osgood. Rev. Bras. Enf.; $28: 43-53,1975$.
\end{abstract}

\section{INTRODUÇÃO}

A dor é um sintoma subjetivo, cuja intensidade, tipo, duração, freqüência, tolerância e manifestações objetivas são características de cada indivíduo e resultantes de suas condições anátomofisiológicas, psicológicas e dos fatores sócio-culturais que vão determinar seu comportamento face a esta experiência.

A dor é necessária e um dos mais importantes sinais de defesa orgânica contra os agentes agressores de qualquer natureza, mas ao mesmo tempo é indesejável pelo ser humano por causar desconforto, ansiedade e ser essencialmente desagradável.

Pesquisadores em diversas áreas de conhecimento têm procurado estudar este sintoma e medí-lo; dados os fatores já citados, a busca de um instrumento preciso para este fim tem sido uma preocupação constante. Nas pesquisas realizadas por enfermeiras, nos Estados Unidos da América do Norte, os critérios utilizados para a avaliação desejada têm se mostrado, até certo ponto, insatisfatórios - controle dos sinais vitais, testes de ansiedade, quantidade de analgésicos aplicados - e há recomendação para que novos estudos sejam realizados e investigados outros instrumentos e critérios.

Tendo tomado conhecimento do método da Escola do Diferencial Semântico de Osgood, pelos trabalhos de Lane ${ }^{2}$, procurou-se aplicá-lo em enfermagem, no estudo da dor.

Lane, em seus estudos preliminares, investigou a palavra dor em 20 sujeitos tendo encontrado, em ordem de freqüência, os seguintes adjetivos para qualifi-

* Professor Adjunto da Escola de Enfermagem da Universidade de São Paulo.

* Professor da Disciplina Enfermagem Cirúrgica da Escola de Enfermagem da Universidade de São Paulo. 
HORTA, W.A. \& Kannebley, Z.M. - Avaliação da dor em paciente submetidos à cirurgia da tiróide pela aplicação do método da Escola diferencial semântica de Osgiod. Rev. Bras. Enf.; $28: 43-53,1975$.

cá-la: ruim, horrível, desagradável, triste, aguda, suportável, terrível, forte, atroz, inevitável, maléfica, necessária, profunda, pungente.

Aplicando-se o instrumento desenvolvido por Lane ${ }^{2}$, em estudo prévio sobre a dor no pós-operatório em pacientes de cirurgia ginecológica, estas consideraram a dor como suja, má, triste, feia, forte, poderosa, muita, instável, incerta, passageira, rápida, quente, pesada, grossa, larga, desnecessária, inútil e dispensável.

Tentar-se-á no presente estudo, verificar se a orientação préoperatória modificaria as qualificações atribuídas à dor.

\section{MÉTODO DO DIFERENCIAL SEMÁNTICO DE OSGOOD}

Este método foi desenvolvido por Osgood $^{3}$ e colaboradores aplicado e estudado em diferentes culturas. Os estudos são basicamente de psico-lingüística, permitindo medir e comparar qualidades atribuídas pelas pessoas a uma palavra. Levaram à proposição, em caráter universal, de um Espaço Semântico, cuja estrutura espacial foi definida por três dimensões: Valorativa, de Potência e da Atividade. Por meio de análise fatorial os pesquisadores identificaram os objetivos que permitem medir e comparar as qualidades atribuídas aos conceitos, sendo que a intensidade é medida pelos valores atribuídos a uma escala de sete intervalos entre os adjetivos opostos, permitindo um gradiente de avaliação de resposta.

Lane $^{1}$ aplicando o método no Brasil, definiu os adjeivos opostos que compõem as escalas de medida de intensidade $e$ encontrou sete fatores que dimensionam o "Espaço Semântico" em nossa cultura.

\section{HIPÓTESE}

A orientação pré-operatória leva os pacientes a avaliarem a dor no pós-operatório, em termos de intensidade na sua qualificação, com valores inferiores ao grupo que não recebe esta orientação.

\section{METODOLOGIA}

População: A população foi de 64 pacientes adultos, do sexo feminino, internacias na $1 .^{\mathrm{a}}$ Clínica Cirúrgica do Hospital das Clínicas de São Paulo. Adotaram-se os seguintes critérios para a seleção dos pacientes; sexo feminino, diagnóstico médico - bócio não neoplásico nem inflamatório; tratamento cirúrgico - tireocidectomia.

Na população estudada a seguinte distribuição foi encontrada: grupo etário - a idade variou de 17 a 76 anos; estado civil -20 solteiras, 32 casadas e as 12 restantes eram viúvas, desquitadas ou separadas; instrução - 45 alfabetizadas e 19 analfabetas; nacionalidade -63 brasileiras e uma paraguaia; grupo etno-cultural - as 64 pacientes se distribuíam segundo a nacionalidade dos pais e avós, a saber: pais e avós brasileiros, (37 pacientes); pais brasileiros e avós portugueses, italianos ou espanhóis (15 pacientes); pais brasileiros e avós alemães (2 pacientes); pais e avós italianos, espanhóis e portugueses (8 pacientes); pais e avós japoneses (1 paciente); pais avós paraguaios (1 paciente).

$\mathrm{Na}$ investigação das condições sócioeconômicas, os dois grupos se assemelham e, na possível interferência de fatores como televisão e rádio que influem nas estereotipias de comportamento não apresentaram diferenças sensíveis.

\section{INSTRUMENTOS}

Foram utilizados dois instrumentos: um roteiro para orientação pré-operatório (Anexo 1) e um formulário adaptado do questionário aplicado por Lane 
HORTA, W.A. \& Kannebley, Z.M. - Avaliação da dor em paciente submetidos à cirurgia da tiróide pela aplicação do método da Escola diferencial semântica de Osgood. Rev. Bras. Enf.; 28 : 43-53, 1975.

(Anexo 2) onde foram incluídos os 7 fatores por ela encontrados:

Fator I. (Valorativo) com as seguintes qualidades quantificadas pelos valores a elas atribuídos na escola, e constituído de quatro pares de adjeivos qualificativos opostos:

limpo-sujo

bom-mau

alegre-triste

feio-bonito

Fator II. Potência:

forte-fraco

fraco-poderoso

muito-pouco

Fator III. Estabilidade:

instável-estável

incerto-certo

passageiro-duradouro

Fator IV. Agilidade:

rápido-lento

quente-frio

Fator V. Simplicidade:

simples-complicado

fácil-difícil

Fator VI. Dimensão:

largo-estreito

pesado-leve

grosso-fino

Fator VII. Utilidade:

indispensável-dispensável

necessário-desnecessário

útil-inútil

O fator I de caráter essencialmente atitudinal está relacionado com o fator VII também valorativo porém num sentido mais pragmático, de utilidade. O fator II diretamente relacionado com a dimensão potência está relacionado ao fator VI sendo que este indica não tanta "força" porém "tamanho". O fator III se associa à atividade denotando em nossa cultura a estabilidade, a este se relaciona o fator IV porém num sentido de agilidade. $O$ fator $\mathrm{V}$ parece se associar aos três fatores básicos de Osgood dando a dimensão de maior ou menor complexidade.

\section{MÉTODO E APLICAÇÃO DOS INSTRUMENTOS}

As pacientes foram divididas em dois grupos, um controle e um experimental. A relação das pacientes para compor os grupos foi obtida ao acaso tendo-se unicamente o cuidado de não ter ao mesmo tempo pacientes dos dois grupos evitando possíveis interferências, pela comunicação entre as mesmas.

A pesquisadora $\mathbf{A}$ visitou todas as pacientes do grupo experimental na véspera de suas cirurgias com o objetivo de fazer a orientação pré-operatória seguindo um roteiro pré-elaborado (Anexo 1). Para a explicação dos itens que o compõem foi usada linguagem simples a accessível.

Uma vez conhecedora do nome da paciente, de seu diagnóstico médico e da data da sua cirurgia a pesquisadora $\mathbf{A}$ aproximava-se da paciente chamando-a pelo nome, apresentando-se, informando-a de que seria operada no dia seguinte e convidava-a para uma entrevista onde ela poderia receber algumas informações ou fazer perguntas. As entrevistas foram individuais, mantendo-se a entrevistadora e a entrevistada sentadas em cadeiras colocadas próximas ao leito da paciente. Terminada a entrevista a entrevistadora A despedia-se da paciente, sem entretanto avisá-la de que seria abordada por outra pessoa.

\section{COLETA DE DADOS DE AVALIAÇÁO DA DOR (Anexo 2)}

Para a coleta de dados de avaliação da dor foram usados formulários dati- 
HORTA, W.A. \& Kannebley, Z.M. - Avaliação da dor em paciente sub̄metidos à cirurgia da tiróide pela aplicação do método da Escola diferencial semântica de Osgood. Rev. Bras. Enf.; 28 : 43-53, 1975.

lografados (Anexo 2) constando de três partes: $1 .^{a}$ parte com as instruções de como preencher o questionário para avaliar a dor; $2 .^{a}$ parte com o vocábulo pelo qual a paciente qualificaria sua dor e as vinte (20) escalas de qualificação onde deveria situar sua escolha no intervalo de classificação da escala para quantificar sua intensidade; 3 a $^{\mathrm{a}}$ parte com dados de identificação da paciente e caracterização sócio-cultural.

Para preenchimento do questionário de avaliação a pesquisadora $B$ visitou todas as pacientes entre o $2 .^{\circ}$ e $3 .^{\circ}$ dia após a cirurgia. Apresentava-se à paciente, dirigia-lhe algumas palavras em que se mostrava interessada pelo seu estado de recuperação, procurava se inteirar do grau de escolaridade e a convidava a responder-lhe algumas perguntas. Não houve rejeições. Se a paciente era alfabetizada, era-lhe entregue o questionário impresso e uma caneta pedindo-se que lesse com atenção e respondesse e que só fizesse perguntas se houvesse algum ponto obscuro. Para as paciente analfabetas foi necessário o auxílio da pesquisadora que além de dar as instruções também lia vagarosamente as palavras extremas de cada escala e anotava a resposta apontada no intervalo pela paciente.

\section{ANÁLISE DAS RESPOSTAS}

Cada escala de qualificação foi graduada pela atribuição de valores numéricos descontínuos $0,+1,+2,+3$ no sentido positivo e $-1,-2,-3$ no negativo.

A grandeza final numérica, definindo uma intensidade (positiva, negativa ou nula) para cada fator de análise foi obtida pela soma algébrica dos números atribuídos pela paciente, em cada escala componente.

Obteve-se a média e o desvio padrão de cada um deles pela soma dos valores atribuídos pelas 32 pacientes de cada grupo. A seguir estes resultados foram submetidos ao teste de hipótese ao nível de significância de 0,10 .

A análise da estereotipia de respostas e dos índices de contradição interna foi feita pela determinação dos Quartis da distribuição da freqüência. Assim os valores contidos Quartil 1 foram considerados índices de estereotipia e os contidos no Quartil 4 foram considerados indicadores de elevada contradição interna.

\section{RESULTADOS}

Distribuição das médias e desvios padrões dos fatores de I a VII nos grupos controle e experimental.

\begin{tabular}{|c|c|c|c|c|}
\hline \multirow{2}{*}{ FATORES } & \multicolumn{2}{|c|}{ GRUPO CONTROLE } & \multicolumn{2}{|c|}{ GRUPO EXPERIMENTAL } \\
\hline & MEDIA & $\begin{array}{l}\text { DESVIO } \\
\text { PADRÁO }\end{array}$ & MEDIA & $\begin{array}{l}\text { DESVIO } \\
\text { PADRÃO }\end{array}$ \\
\hline I & $-1,17$ & 1,28 & $-0,57$ & 1,40 \\
\hline II & 0,29 & 1,91 & 0,30 & 1,41 \\
\hline III & $-0,5 \cdot 1$ & 1,43 & 0,07 & 1,28 \\
\hline IV & 0,53 & 1,67 & 0,53 & 1,34 \\
\hline $\mathrm{V}$ & 0,46 & 1,93 & $-0,06$ & 1,51 \\
\hline VI & 0,71 & 1,68 & 0,05 & 1,50 \\
\hline VII & 0,17 & 2,03 & 0,68 & 1,61 \\
\hline
\end{tabular}


HORTA, W.A. \& Kannebley, Z.M. - Avaliação da dor em paciente submetidos à cirurgia da tiróide pela aplicação do método da Escola diferencial semântica de Osgood. Rev. Bras. Enf.; 28 : 43-53, 1975.

De uma maneira geral as médias do grupo experimental foram menores que as do grupo controle com exceção do fator IV que foi igual e a do fator VII que foi maior.

Os dois grupos consideraram a dor no fator I valorativo (emocional) como suja, má, feia e triste; o teste da diferença das médias ao nível de 0,10 foi de 1,79 , considerado siginificante para o grupo experimental.

No fator II (Potência), os dois grupos não diferiram significantemente, mas em termos de potência, a dor foi considerada forte, muita e poderosa.

Fator III, ligado à Atividade, porém em termos de estabilidade foi significante para o grupo experimental $(1,71)$, aplicado o teste de hipóteses ao nível de 0,10 . O grupo controle considerou a dor instável, incerta e passageira e o grupo experimental, estável, certa, duradoura.

Fator IV - Atividade em termos de agilidade os dois grupos foram iguais considerando-a rápida e quente.

Fator V (Simplicidade) - Os valores não foram significantes ao nível de 0,10 embora o grupo controle tenha considerado a dor como simples e fácil e o grupo experimental como difícil e complicada.

Fator VI (relacionada à dimensão) O grupo experimental diferiu significantemente ao nível $(1,67)$ 0,10 do grupo controle. Ambos consideraram a dor larga, pesada e grossa.

Fator VII ligado à utilidade e pragmatismo, os resultados não foram significantes ao nivel de 0,10 . Os dois grupos consideraram a dor como indispensável, útil e necessária.

Análise das estereotipias ou contradições internas das respostas dos dois grupos. - Foram considerados índices de estereotipias os Quartis abaixo de 0,45 e alta contradição interna os Quartis acima de 1,10. O grupo experimental mostrou maior índice de estereotipia em geral em relação ao grupo controle. Os resultados encontrados foram: estereotipia no fator I nos dois grupos e no fator IV no grupo experimental. Alto índice de contradição interna foi encontrado no fator VI no grupo experimental e no grupo controle nos fatores II, $\mathrm{V}$ e VII.

\section{DISCUSSÃO}

Na escolha do grupo a ser estudado preferiram-se pacientes que seriam submetidas à cirurgia da tiróide pelo fato de que as afecções desta glândula, excluindo-se as tireoidites e as neoplasias, serem praticamente indolores, desta maneira seria possível uma avaliação mais precisa da dor no pós-operatório. Os estudos já realizados sobre a dor têm demonstrado sobejamente a interferência do sexo, idade e principalmente dos fatores sócio-culturais. A população selecionada foi somente do sexo feminino, e nos dois grupos, tanto a idade, como estado civil, grau de escolaridade, condições sócio-econômicas e culturais foram semelhantes, havendo homogeneidade na amostra.

Evitando-se a presença simultânea na enfermaria de pacientes dos dois grupos controlou-se uma possível comunicação que poderia interferir nos resultados. Os dois grupos seguiram a rotina estabelecida no hospital para a cirurgia específica e a influência dos fatores ambientais, sem qualquer interferência das pesquisadoras.

Nos resultados encontrados a média dos valores atribuídos pelo grupo experimental foi menor que a do grupo controle com duas exceções, a do fator IV que foi igual e a do fator VII que foi ligeiramente maior embora não significante ao nível de 0,10. Diante dos fatores identificados por Lane a hipótese 
HORTA, W.A. \& Kannebley, Z.M. - Avaliaçāo da dor em paciente submetidos à cirurgia da tiróide pela aplicação do métodó da Escola diferencial semântica de Osgood. Rev. Bras. Enf.; $28: 43-53,1975$.

foi parcialmente confirmada quanto aos fatores I (valorativo), III (atividade-estabilidade) e o fator VI (potência, mais no sentido tamanho). Considerando-se as três dimensões universais de Osgood (valorativo, potência e atividade) o grupo experimental ao receber a orientação pré-operatória teve diminuída significantemente a avaliação da dor e a hipótese foi confirmada.

Para explicar o fato do grupo experimental ter considerado a dor como complicada e difícil em contraposição ao grupo controle que a considerou simples e fácil, embora os resultados não tenham sido estatisticamente significantes e a média relativamente baixa $(-0,06)$ pode-se aventar duas suposições, a primeira por ser a amostra de 32 pacientes, e a segunda, porque várias pacientes deste grupo tiveram muita tosse no pós-operatório, eram tabagistas e explicaram que ao tossir a dor se manifestava. Isto alertou para esta variável que não foi controlada, o fumo principalmente do cigarro como agente irritante do trato respiratório associado à entubação para a anestesia geral agravam o problema da tosse pós-operatória. A enfermagem no plano de cuidados pré-operatórios, seja qual for o tipo de cirurgia, deve recomendar aos pacientes fumantes a abstenção do cigarro pelo menos uma semana antes da data da cirurgia e a realização de exercícios respiratórios para diminuir as complicações pulmonares e das vias aéreas superiores.

Quanto ao fator VII, a média do grupo controle foi de 0,17 e a do experimental 0,68 não significante ao nível de 0,10 ; o fato deste grupo ter média maior considerando a dor pós-operatório como indispensável, necessária e útil parece mostrar que a orientação pré-operatória leva o paciente a valorizar mais pragmaticamente a dor sentida e compreender a sua utilidade.

Foi interessante observar que a orientação pré-operatória, embora dada individualmente, levou o grupo experimental a menor grau de contradição interna em relação ao controle, denotando maior estereotipia, o que evidencia a imparcialidade da pesquisadora ao dar a mesma orientação trinta e duas vezes. A estereotipia valorativa emocional, comum nos dois grupos, é explicada não só dentro da própria cultura como pelo fato fisiológico do ser humano sentir desprazer com a dor; esta leva o individuo à tensão e surge a necessidade de eliminar este estado de ansiedade. Embora a dor seja um elemento de defesa do organismo, registrando sinais de anormalidade, todo ser humano, em condições normais tem necessidade básica de repulsa à dor.

Ao se analisar o roteiro de orientação pré-operatória (Anexo 1) observa-se que o fator dor constituiu 1/12 de seus tópicos, não sendo portanto o assunto de mais relevo na orientação dada. Podendo-se inferir que a orientação como um todo, na ação sinérgica de cada um de seus tópicos foi talvez a responsável pela confirmação da hipótese levantada.

\section{CONCLUSÕES}

1. O método do Diferencial Semântico de Osgood mostrou ser um instrumento parcialmente capaz de avaliar o significado psicológico da dor sentida pelo paciente no pós-operatório de tireoidectomia.

2. A orientação pré-operatória modificou significantemente em termos de intensidade na sua qualificação ao nível de 0,10 a avaliação da dor quanto aos fatores I, III e VI respectivamente relacionados às dimensões: valorativa, potência e atividade. 
HORTA, W.A. \& Kannebley, Z.M. - Avaliação da dor em paciente submetidos à cirurgia da tiróide pela aplicação do método da Escola diferencial semântica de Osgood. Rev. Bras. Enf.; $28: 43-53,1975$.

\section{REFERENCIAS BIBLIOGRÁFICAS}

1. LANE, Silvia Maurer - Semantical Differential Scales for Portuguese speakers in Brazil International Journal of Psychology, 8 (2). 147-152, 1973.

2. LANE, Silvia Maurer - Significado Psicológico de Palavras em diferentes grupos sócio-culturais Tese de dou- toramento Revista de Psicologia Normal e Patológica. Ano XVIII (3-4) : 3-152, julho-dezembro 1972.

3. OSGOOD, Charles E. - Exploration in Semantic Space: a Personal Diary Journal of Social Issues, 27 (4) : 564, 1971.

\section{BIBLIOGRAFIA CONSULTADA}

DIERS, SCHMIDT, Mc BRIDE and DAVIS

- The effect of nursing interaction on patients in pain. Nursing Research, 21 (5) : 419-427, sep-oct, 1972.

MCCAFFERY, M. - Nursing Management of the Patient with Pain J.B. Lippincott Co, Philadelphia, 1972.

ZBOROWSKI, Mark - Cultural components in responses to pain in "A Sociological Framework for Patient Care" John Wiley \& Sons, New York, pags. 258-271, 1966. 


\section{ITENS A SEREM ABORDADOS E ESCLARECIDOS AOS PACIENTES}

1. Bócio

2. Tireoidectomia

3. Anestesia Geral

4. Limpeza da pele e tricotomia

5. Jejum pré-operatório

6. Retirada de próteses dentárias

7. Medicação pré-anestésica

8. Dor pós-operatória

9. Cuidado com a ferida cirúrgica

10. Posição de Trendelemburgo no P.O.

11. Deambulação

12. Respiração profunda
ESCLARECIMENTOS

Aumento da glândula do pescoço. Fazer o paciente tocar com seus dedos o crescimento.

Mostrar o local em que será feita a incisão. Retirada da parte aumentada da glândula. $\mathrm{O}$ restante da glândula é suficiente para manter a função.

Produz sono e não deixa sentir dor durante a cirurgia.

Vantagens da pele limpa e sem pelos e penugem para a cirurgia.

Justificar a necessidade de manter jejum após o jantar até a hora da operação.

Verificar se usa próteses dentárias. Em caso positivo, explicar porque e quando retirá-las e recolocá-las. Local para guardá-las.

Informá-lo que 45 minutos antes de seguir para a sala de cirurgia receberá uma injeção IM e os objetivos da mesma.

Informá-lo de que se sentir dor no pescoço e ao deglutir no P.O. não deverá ficar preocupado pois isto é normal devido ao corte. Tranquilizá-lo quanto a possível sofrimento dizendo que a enfermeira lhe dará remédios quando sentir dor.

Não colocar a mão sobre o corte.

Explicar em que posição ficará no P.O. e as vantagens da mesma.

Informá-lo que deverá sair do leito e caminhar tão logo o médico dê permissão e que isto ocorre 24 a 48 horas após a cirurgia. Mostrar-lhe as vantagens da de ambulação e assegurar-lhe que uma enfermeira o ajudará caso necessite de auxílio.

Aconselhar o paciente a fazer movimentos respiratórios profundos no pós-operatório mostrando-lhe as vantagens de movimentos amplos do pulmão. 


\section{ANEXO N.O 2}

\section{INSTRUÇõES}

Esta pesquisa vai medir o que significam certas coisas para algumas pessoas. Nas páginas seguintes você encontrará uma palavra no alto de cada página e logo em baixo algumas escalas, cada uma com dois adjetivos opostos, um em cada ponta.

Você irá responder fazendo um $\mathrm{X}$ em cada escala para mostrar o que a palavra (no alto da página) quer dizer para você.

\section{GATO}

EXEMPLO:

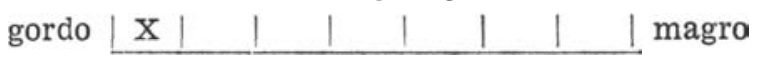

1) Se V. marcar no $10^{\circ}$ espaço (como aí) é que V. acha que gato é sempre gordo.

Se você no último espaço, assim:

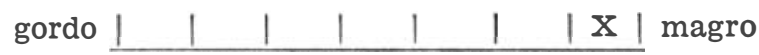

é que V. acha que gato é sempre magro.

2) Se V. achar que gato é na maioria das vezes, mas não sempre, gordo, V. marca assim:

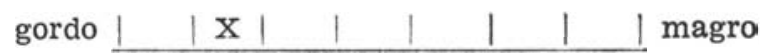

Se V. achar que é na maioria das vezes magro, marque assim:

gordo $1|1||x| \mid$ magro

3) Se V. achar que gato é às vezes gordo, V. marca assim:

gordo $1 \quad|\quad| x|1| 1$ magro

Ou, se às vezes magro, assim:

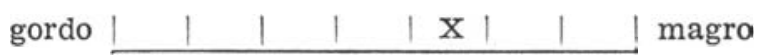

4) Mas se V. achar que gato não é nem gordo nem magro, marque assim:

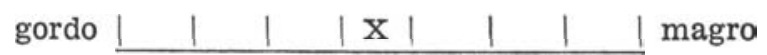

Isto foi uma exemplo. Para cada palavra V. encontrará muitas escalas. V. deverá decidir para cada uma qual a resposta que diz aquilo que V. acha da palavra no alto das páginas.

SEJA SINCERO 


\section{A DOR DEPOIS DA OPERAÇÃO}

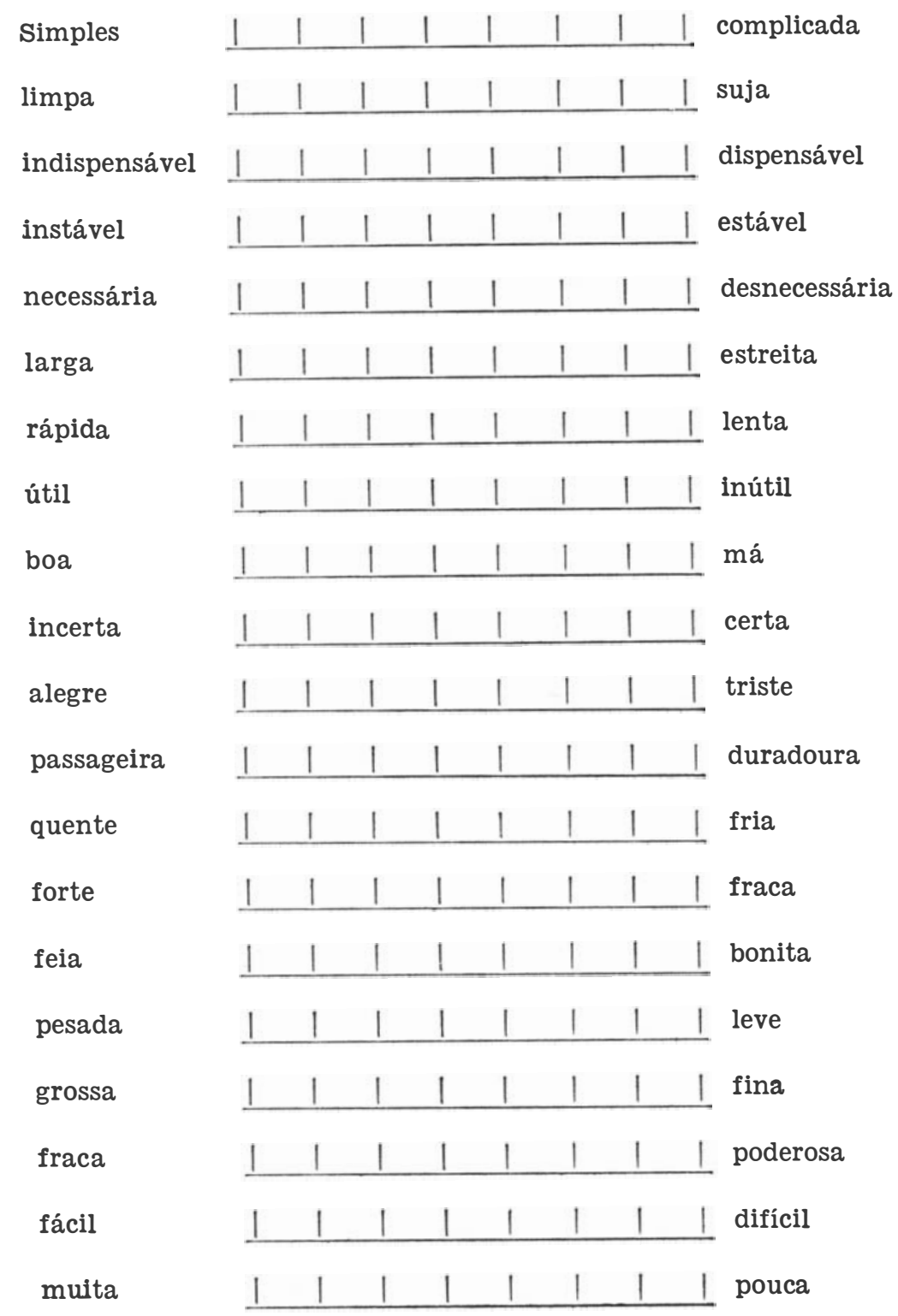


Nome:

Idade:

N. ${ }^{\circ}$ de filhos:..... Ocupação:

Class. Social:

Ocupação do Marido: .Nac. do Marido:

Data da Operação:........ Operação:

Recebeu explicações antes de operar? SIM |_l NÃO |_l

De quem?

Religião: Escolaridade:

1) País de origem dos pais: Pai:

Mãe

Avô Paterno:

Avô Materno:

Avô Paterna:

Avó Materna:

2) Língua falada em casa:

3) Você já esteve interna antes? SIM I_l NÃO

Qual hospital? ...................... Quanto tempo?.

4) Você sempre conversa com:

Vizinhos 1 _ Comp. de enfermaria 1 _ Parentes $\mid \_l$

Func. do Hospital !__

5) O que costuma fazer?

Bordar I__ Costurar I_l Cozinhar I_l Lavar e passar I_l

Cuidar dos filhos I_ l Cuidar da casa I_l outros I_

Quais?

6) Você tem outras obrigações além do cuidado da casa?

SIM I_ I NÃO I_ I

Qual?

7) Você vai ao cinema? SIM |_l NÃO | _

Só foi uma vez l__ Algumas vezes no ano I__ Uma vez no ano I__

Uma vez por mês l__ Mais de uma vez por mês I_l

8) Lê revistas? SIM I_ $\mid$ NÃO I_ $\mid$ Qual?

9) Lê livros? SIM |__ NÃO |_l Qual?

10) Assiste televisão? SIM I_

Qual programa que mais gosta?

11) Quais destes objetos são de sua propriedade?

casa I_l Máquina de lavar roupa carro rádio
Aspirador de pó !_

Televisão
Enceradeira !_!

Vitrola I__

Geladeira 